\title{
PERANAN ORANG TUA DALAM MENUMBUHKAN KARAKTER ANAK DENGAN UPACARA BAYUH OTON
}

\author{
I MADE SUJANA \\ Institut Hindu Dharma Negeri Denpasar \\ madesujana@ihdn.ac.id
}

\begin{abstract}
Character education of children cannot be separated from the role of parents in providing early upbringing to their children. Education of parents to determine how their upbringing to their children in the rapid technological advances becomes a challenge for parents to be able to educate their children not to be involved in promiscuity.

The role of parents in fostering children's character can be done through various ways, such as to instill religious values, involving a wide range of organizations and self-purification through Bayuh oton ceremony.

The obstacles faced by parents in fostering children's character are influenced by external factors and internal factors. Bayuh Oton ceremony in fostering children's character is best done through rituals Bayuh oton, according to date of birth and a ceremonial procession Bayuh oton.
\end{abstract}

\section{Key words: Parents' Roles, Children's Character, Bayuh Oton}

\section{Latar belakang}

Manusia merupakan mahluk ciptaan Tuhan yang paling tertinggi derajatnya dibandingkan deengan mahluk ciptaan lainnya. Hal ini ditandai manusia memiliki Tri Pramana yaitu Sabda, Bayu, Idep. Dengan kelebihan idep ini manusia mampu membedakan mana perbuatan yang baik yang harus dilakukan dan mana perbuatan buruk yang harus dihindari. Dengan kelebihan idep ini manusia diharapkan dapat memiliki karakter yang baik dalam kehidupan di masyarakat.

Dalam persepsi pendidikan, terdapat tiga lembaga utama yang berpengaruh dalam perkembangan kepribadian seorang anak yaitu lingkungan keluarga, lingkungan sekolah dan lingkungan masyarakat, yang selanjutnya dikenal dengan Tri Pusat Pendidikan. Dengan adanya perkembanagan Teknologi sekarang ini yang merajalela membuat pengaruh besar pada masyarakat dan hal ini tersebut dapat mempengaruhi perkembangan kepribadian seorang anak.

Suatu hal yang tidak dapat dipungkiri bahwa pembangunan disegala bidang, manfaatnya semakin dirasakan oleh semua kalangan. Revolusi informasi menyebabkan dunia terasa semakin kecil, semakin mengglobal, dan sebaliknya privacy seakan tidak ada lagi. Berkat revolusi informasi kini orang telah terbiasa berbicara tentang globalisasi dunia dengan moderenisasi sebagai ciri utamanya. Dengan teknologi semakin canggih, hampir terjadi diplosok dunia segera diketahui dan ketergantungan antar bangsa semakin besar. Efek dari globalisasi itulah mendatangkan kebahagian dan juga menimbulkan masalah serta kebijakan baru bagi manusia. Efek samping itu ternyata berdampak sosiologi dan psikologis. Contoh dari efek globalisasi adalah banyak anak menyalahgunakan teknologi, penggunaan obat-obatan terlarang karena pengaruh teman. Nilai-nilai 
kemasyarakatan yang selama ini dianggap dapat dijadikan sarana penentu dalam berbagai aktifitas menjadi kehilangan fungsinya. (Harahap,1999:83)

Untuk menyikapi fenomena global seperti itu, peran orang tua untuk menanamkan nilai-nilaikeagamaan dalam menumbuhkan karakter anak dan remaja secara dini dibutuhkan. Dalam hubungan ini, keluarga diharapkan sebagai lembaga sosial yang dasar untuk mewujudkan pembangunan kualitas manusia dalam lembaga ketahanan untuk mewujudkan masyarakat yang berkarakter. Pertama keluarga merupakan titik awal keberangkatan sekaligus sebagai modal awal perjalanan hidup mereka. (Harahap, 1999:14)

Dalam hal ini pendidikan karakter pada anak tidak bias terlepas dari peran orang tua dalam menanamkan nilai-nilai agama yang merupakan pendidikan dasar yang harus diterapkan kepada anak sejak dini. Hal ini mengingat pribadi mudah dibentuk, karena anak masih dibawah pengaruh lingkungan keluarga. Pendidikan anak dalam keluarga merupakan sebuah kewajiban dan membutuhkan perhatian yang serius. Mengingat fungsi orang tua dalam buku Nitisastra dinyatakan sebagai berikut: 1. Amertuakan artinya orang tua berfungsi sebagai yang melahirkan anak. 2. Maweh Binojana artinya fungsi orang tua memberikan makanan yang bergizi. 3 . Matulung Urip artinya fungsi orang tua memberikan perlindungan pada anak dikala sakit dan mendapat bahaya. 4. Mangupadaya artinya memberikan pendidikan yang layak pada anak dan 5. Sinangaskara artinya fungsi orang tua menyucikan lahir dan bhatin anak melalui Upacara keagamaan.
Fungsi yang terkemuka di atas disimpulkan bahwa keluarga/ orang tua merupakan sumber dari segala perkembangan karakter anak. Peran orang tua dalam menumbuhkan karakter anak juga berpedoman pada nilai-nilai budaya dan tradisi yang terdapat dalam masyarakat. Upaya menumbuhkan karakter anak, khususnya umat Hindu di Bali sangat percaya dengan melaksanakan suatu Upacara Manusia Yadnya secara umum dilakukan sejak anak itu berada dalam kandungan sampai menginjak remaja, dapat menuntun atau menumbuhkan ahlak Budi pekerti atau karakter manusia itu sendiri, lebih-lebih Upacara Manusia Yadnya yang lebih mengkhusus seperti " mebayuh oton" bagi kelahiran Sapta Wara Redite.

Menurut Budha Gautama (2004:2) kelahiran manusia pada sapta Wara redite, apabila kelahiran seseorang pada hari radite, Dewanya Sang Hyang Indra, kalanya sang Dorakala, Butanya Sang Buta Catur Pata, Kayunya: kayu putih. Manuknya: Bio, Wayangnya panji, Lintangnya: Lintang Tendas Mamereng, Rasinya: Kumba.

Itulah yang menjadi gangguan kehidupan bagi orang yang lahir pada hari radite, hingga dikatakan panes. Hingga banyak jenis penyakit yang bersarang pada diri orang tersebut, yang oleh umat Hindu di Bali disebut sakit aba-abaan dumadi antara lain: borok, panes tinggi, panas dingin, lesu serta layu. Apabila perempuan kematiannya tatkala melahirkan bila orang lelaki kematiannya tatkala mengamuk, oleh karenannya lakukanlah bayuh oton.

\section{Masalah pokok}

Masalah pokok yang merupakan pembatasan masalah dalam tulisan ini adalah: bagaimanakah peran orang tua dalam menumbuhkan karakter anak di 
Banjar Dresta Sudharma Wates Tengah, apa hambatan-hambatan orang tua dalam menumbuhkan karakter anak, dan apakah Upacara mebayuh oton dapat menumbuhkan karakter yang baik bagi anak dan remaja.

\section{Tujuan kajian}

a. Secara umum tujuan dari penulisan ini adalah memberikan gambaran pengetahuan dan pemaham masyarakat Bali khususnya dan warga Banjar Dresta Sudharma Wates Tengah tentang pentingnya Upacara Bayuh oton sebagai Upaya menumbuhkan karakter yang baik bagi anak dan Remaja.

b. Secara Khusus dari penulisan ini adalah untuk mendeskripsikan bagaimana peran orang tua dalam menumbuhkan karakter anak dan remaja, untuk mengetahui apa saja hambatan-hambatan orang tua dalam menumbuhkan karakter anak dan remaja dan untuk mengetahui apakah Upacara Bayuh Oton dapat menumbuhkan karakter anak.

\section{Metodologi}

Metode penelitian ini menggunakan penelitian lapangan dengan menggunakan pendekatan kualitatif dengan maksud berusaha mengungkapkan keadaan yang bersifat alamiah secara holistic. Pendekatan kualitatif menekankan pada kesan tidak bertolak dari teori secara dedukatif melainkan berangkat dari fakta sebagaimana adanya. (Ali: 2002:5859).

Sumber data yang diperoleh dalam penulisan ini adalah data primer yang merupakan keterangan-keterangan atau informasi yang diperoleh dari masyarakat Banjar Dresta Sudharma Wates Tengah diantaranya beberapa tabah dimasyarakat, Pandita atau Sri Mpu, tokoh adat yang mengerti mengenai peranan orang tua dalam menumbuhkan karakter anak melalui upacara bayuh oton di Banjar Dresta Sudharma Wates Tengah.

Selain data primer juga dalam penulisan ini menggunakan data sekunder antara lain buku-buku, jurnal, hasil penelitian orang lain yang relevan dengan tulisan ini.

Adapun metode yang dipakai dalam pengumpulan data dalam penulisan ini adalah metode observasi, wawancara (interview) dan metode kepustakaan. Data yang diperoleh kemudian dianalisis melalui tiga jalur kegiatan yang merupakan satu kesatuan yaitu 1). Reduksi 2). Penyajian 3). Penarikan Kesimpulan.

\section{Landasan Konseptual dan Analisis}

A.Landasan Konseptual

1.Pengertian dan peran orang tua

Pengertian orang tua dalam kamus Besar Bahasa Indonesia orang tua mempunyai Ayah, Ibu Kandung, orang yang dianggap Tua (Cerdik, Pandai, Ahli Dan Sebagainya), orang-orang dihormati/ disegani (Depdikbud 1997:706)

Sebutan orang tua ditujukan bagi orang yang telah berumah tangga yang telah dimulai dengan perkawinan/wiwahe (Titib,1998:393), pasangan yang menjalin hidup Rumah tangga sudah menjadi calon orang tua bagi anaknya. Menurut ajaran Agama Hindu yang berfungsi sebagai kepala keluarga adalah Ayah, seorang Ibu adalah pengasuh atau Pembina keluarga terutama anak-anak yang lahir dalam keluarga itu (Tim Penyusun, 1994:107). Selain kehadiran seorang anak dari perkawinannya tersebut maka kedua pasangan tersebut mulai disebut sebagai orang tua. 


\section{Pengertian Karakter}

Menurut Yahya (2010:1) karakter adalah sikap pribadi yang stabil hasil proses konsulidasi secara progresif dan dinamis, integrasi pernyataan dan tindakan. Sedangkan menurut Ibrahim (2006:50) karakter adalah sebuah system keyakinan dan kebiasaan yang mengarahkan tindakan seorang individu.

Menurut Kamus Besar Bahasa Indonesia karakter adalah sifat-sifat kejiwaan, ahlak atau Budi Pekerti yang membedakan seseorang dengan orang lain. Jika pengetahuan mengenai karakter seseorang itu dapat diketahui, maka dapat diketahui pula bagaimana individu tersebut akan bersikap. Menurut pendapat para ahli tersebut, maka pengertian karakter dapat disimpulkan sebagai suatu keyakinan yang terjadi tanpa ada pemikiran lagi karena sudah tertanam dalam pikiran.

Menumbuhkan karakter berarti mendidik untuk berfikir tentang pendidikan dapat kita mudahkan dengan membuat analogi sebagai seorang petani yang hendak bertanam diladangnya. Anak yang akan di didik dapat diibaratkan sebagai tanah, isi pendidikan sebagai bibit atau benih yang akan ditaburkan, sedangkan pendidik diibaratkan sebagai petani. membangun karakter anak, yang ditadak lain adalah mendidik kewajiban anak, tidak semudah dan sesederhana menanam bibit (Arikunto, 2004:1).

\section{Mebayuh Oton}

Menurut Wikarman (1995:17) menyebutkan bahwa Bayuh Oton adalah Upacara menurut kelahiran untuk menetralisir pengaruh-pengaruh yang tidak baik yang ada pada diri manusia. Kata Bayuh sejenis dengan kata Dayuh, Dayuh dalam bahasa Bali artinya Sejuk. Bayuh dimaksudkan menyejukkan diri manusia dari hal-hal yang bersifat keras atau panas kelahirannya.

Menyejukkan juga berarti menetralisir, dengan pengertian tersebut maka menumbuhkan karakter melalui Upacara Bayuh oton, menetralisir pengaruh-pengaruh yang tidak baik pada diri anak agar terhindar dari pengaruh sifat-sifat negative sehingga tumbuh menjadi manusia yang memiliki budi pekerti yang luhur.

\section{B.Analisis}

Hasil penelitian ini menggunakan analisis Deskritif kualitatifn terhadap data yang diperoleh dilapangan baik data primer maupun data sekunder yang terkait dengan Rumusan Maslah dalam penulisan ini. Adapun hasil analisis dari tiga permasalahan dalam tulisan/penelitian ini adalah sebagai berikut:

1.Peranan orang tua dalam menumbuhkan karakter anak di Banjar Dresta Sudharma Wates Tengah.

Peranan merupakan pola prilaku yang diharapkan seseorang yang memiliki status atau posisi tertentu dalam organisasi seperti dalam keluarga. Peranan orang tua sangatlah penting dalam menumbuhkan karakter seorang anak, sebab sosialisasi dalam hidup bermasyarakat seseorang anak berasal dari orang tua mereka masingmasing.

Dari pola didik orang tua yang mereka terapkan maka seorang anak dapat merekam apa yang mereka terima dari orang tua mereka, segingga pola didik yang diberikan oleh orang tua mereka akan mereka terapkan dalam kehidupan bermasyarakat. 
Ada beberapa cara yang dilakukan orang tua di Banjar dresta Sudharma Wates Tengah dari hasil wawancara yang penulis dapatkan dari para informan adalah sebagai berikut:

\section{a.Menanamkan Nilai Agama (Religus)}

Setiap orang tua memang menginginkan anaknya kelak menjadi anak yang baik dalam kehidupannya, agar menjadi anak yang sesuai dengan harapan orang tua. Seperti yang diungkapkan oleh Suamba, setiap orang tua sangat menginginkan anaknya dapat hidup bermasyarakat dengan baik, banyak cara yang ditempuh orang tua dalam menanamkan sikap beragama sejak didni pada anaknya agar dapat membedakan mana perbuatan yang baik yang harus dilakukan dan mana perbuatan yang tidak baik atau yang dilarang oleh Agama yang harus dihindari (Suamba, wawancara, tanggal 5 Juni 2015).

b.Mengikutsertakan dalam berbagai kegiatan organisasi

Peran orang tua dalam mendidik anak itu sangat penting, yang mana mendidik itu menjadi acuan dalam berprilaku apabila anak tersebut keluar lingkungan keluarga dan mengenyam pengalaman-pengalaman di lingkungan masyarakat.

Adanya berbagai macam alas an yang timbul dari pemikiran orang tua, maka muncul pula cara mereka untuk menumbuhkan karakter pada anak mereka masing-masing. Diantanya cara yang dilakukan oleh Pawana yang berpatisipasi sebagai perbekel Duda Timur, beliau mengungkapkan bahwa bahwa cara beliau dalam menumbuhkan karakter pada anaknya beliau menyarankan pada anaknya untuk mengikuti berbagai kegiatan organisasi baik yang ada di lingkungan sekolah maupun dilingkungan masyarakat terutama organisasi yang bersifat keagamaan, dengan seperti itu maka anak akan mengerti sendiri betapa pentingnya menerapkan prilaku beragama dalam segala kehidupan baik sekolah, masyarakat dan dimana saja (Pawana wawancara, tanggal 30 Juni 2015)

c.Penyucian lahir dan batin dengan Upacara Bayuh Oton

kelahiran manusia kedunia memiliki karakter yang berbeda-beda, hal ini ditegaskan dalam pustaka suci Wrehaspati Tatwa sebagai berikut:

“ Apam akuweh ngaranin wasana ngarani ikanggimawe Jadma, ia ta binate pala ring paratra"

Artinya:

"Sebab banyak yang disebut wasana namanya perbuatan dikerjakan terdahulu itu dinikmati di alam baka pada penjelmaanya lagi"

Lebih lanjut ditegaskan oleh Budha Gautama: hari kelahiran seseorang tidak sama satu sama lainnya. Setiap kelahiran akan membawa serta sifat-sifat serta ciri-ciri tertentu yang disebut pewacakan kelahirannya antara lain, hari sapta wara, hari panca wara dan pawukan dan dari pemacakan tersebut menimbulkan baik buruk kelahiran seseorang. Jenis derita bawaan akibat dari pawacakan menurut Singin Wikarman (1995:13) dapat dientaskan melalui perbuatan baik Tapa, Brata, Yoga, Semadi, Sentuhan orang suci dan dengan Upacara Ritual. Upacara Bayuh Oton adalah upacara menurut kelahiran untuk menetralisir pengaruh-pengaruh yang tidak baik yang ada pada diri manusia. 
Menurut Ida Pandita Mpu Tri Sadhu Dasanata yang sering menangani Upacara Bayuh Oton menyatakan bahwa, banyak anak-anak yang melaksanakan upacara bayuh oton sedikit banyak dapat mempengaruhi atau menumbuhkan karakter anak untuk menuju ahlak yang mulia (Ida Pandita Tri Mpu Sadhu Dasanata wawancara tanggal 2 Juli 2015).

2. Upacara mebayuh oton dapat menumbuhkan karakter anak di Banjar Dresta Sudharma Wates Tengah.

Derita bawaan dapat dientaskan melalui Upacara ritual seperti mebayuh oton. Hal ini secara tegas diungkapkan oleh Ida Pandita Tri Mpu Sadhu Dasanata bahwa Upacara Bayuh oton menurut kelahiran dapat menetralisir pengaruh-pengaruh yang tidak baik yang ada pada diri manusia (Wawancara tanggal 2 Juli 2015)

Lebih lanjut Wikarman (1995:17) menegaskan kata Ruwatan berasal dari kata Ruat yang berarti menyucikan, namum kemudian berarti menetralisir pengaruhpengaruh jahat misalnya pengeruatan Sudhamala.

Baik ruwatan maupun Bayuh oton selalu mempergunakan jenis sesajen atau bebanten. Bebanten/sesaji disamping berfungsi sebagai persembahan kepada Betare Kala, juga mempunyai arti yang sangat dalam dan bernilai magis. Dalam upacara bayuh oton atau ruwatan selalu dilengkapi dengan " pengelukatan" yang berfungsi pembersihan secara spiritual. Dengan demikian bayuh oton atau ruwatan lebih mengarah pada arti penyucian atau pembersihan. Sebagai upaya untuk menumbuhkan sifat-sifat satwam dan memiliki karakter yang baik.

\section{Kesimpulan Dan Saran}

a.Kesimpulan

Peranan orang tua dalam menumbuhkan karakter anak di Banjar Dresta Sudharma wates Tengah dapat dilakukan melalui beberapa cara yaitu: 1). Menanamkan nilai-nilai Agama sejak dini dilingkungan keluarga, 2). Mengikutsertakan anak dalam berbagai kegiatan dalam organisasi keagamaan baik disekolah maupun dimasyarakat, 3). Menyucikan lahir batin anak melalui upacara bayuh oton.

Adapun hambatan-hambatan yang dihadapi orang tua dalam menumbuhkan karakter anak meliputi dua faktor yaitu faktor eksternal seperti perkembangan teknologi, pergaulan bebas dan peredaran obat-obat terlarang, dan factor internal seperti sikap keras kepala, sikap egois dan derita bawaan atau karma wasana.

Upacara bayuh oton dapat menumbuhkan karakter anak dengan sarana Upakara/Banten dan Tirta pengelukatan.

\section{b.Saran}

Setiap orang tua hendaknya dapat melakukan fungsi dengan baik sesuai dengan ungkapan NItisastra yaitu: 1). Amertuakan, 2). Mengupadaya, 3). Maweh, 4). Bujojana dan 4). Sinangaskara. 


\section{Daftar Pustaka}

Ananda kusuma, Sri Reshi,1983, Premban Bali Agung, Klungkung, Guma Agung.

Arikunto, Suharsini, 2006. Prosedur penelitian suatu pendekatan praktik. Jakarta: Rineka Cipta.

Awanita, I Made, 2008, membentuk kepribadian anak dalam kandungan, Surabaya, Paramita.

Budha Gautama, Wayan, 2004<warnaning Pawacakan Rare: Kayumas Agung

Hadi, Sutrisno, 1992. Metodelogi Research, Yogyakarta: Andi Offset.

Iqbal, Hasan, 2002. Pokok-pokok Materi Penelitian dan Aplikasi, Ghalia:Indonesia.

Larry P. Nucci, 2004,handbook pendidikn moral dan karakter, Bandung, Nusa Media.

Raka Mas, AA Gede 2004, Membangun masyarakat berkualitas elalui kepedulian pada tata susila dan Budhi Pekerti Hindu Surabaya, Paramita.

Suparta, I Kadek, 2001 “ fungsi Upacara Bayuh Oton Bagi Umat Hindu Di Desa Pikat Kecamatan Dawan Kabupaten Kelungkung" Denpasar IHDN

Truwini, I Made,2009, “ Esensi Upacara Ngotonin Bagi Umat Hindu Di Desa Pakraman Penaban, Kecamatan Karangasem, Denpasar IHDN.

Sumerti, Ni Wayan,2008." Makna dan Fungsi Pengelukatan Sampet Sorong dalam Upacara Manusa Yadnya di Desa Pakraman Lumbung Kelod Sema. Denpasar IHDN.

Wikarman, I Nyoman Singin 1995, Bayuh Oton atau Ruwatan menurut kelahiran, Bangli, Yayasan Widya Shanti 